\title{
Personnel Management to Human Resource Management (HRM): How HRM Functions?
}

\author{
Taslim Ahammad \\ Bangabandhu Sheikh Mujibur Rahman Science \& Technology University (BSMRSTU), Bangladesh
}

\begin{abstract}
Any enterprise now is a significant part of the world economy both in terms of trade and employment. The performance of a business organisation is in part dependent on the capability of its human resource (HR). The knowledge and experience of employees is a source of competitive advantage, however, whether this is realised or not may depend on having the right HR policies. Managers therefore seek to implement best practice, and in multinationals there is the potential for intra-organizational learning across national boundaries. The human being is the most important element in the development process and its ultimate goal. Attention to the management of human affairs and the effort to make man an effective contributing member in the development plans within organizations, is the responsibility of those working in the field of human resources management (HRM) which has become a distinguished field of management worldwide and plays an important role especially in the developing countries. This study discussed personnel management to HRM and how HRM functions.
\end{abstract}

Keywords: personnel, human resource management (HRM), function

\section{Introduction}

The term "human resource management" (HRM) has been commonly used for about the last ten to fifteen years. Prior to that, the field was generally known as "personnel administration". HRM has changed in name various times throughout history. The name change was mainly due to the change in social and economic activities throughout history. Industrial welfare was the first form of HRM.

Personnel administration, which emerged as a clearly defined field by the 1920 s, was largely concerned the technical aspects of hiring, evaluating, training, and compensating employees and was very much of "staff" function in most organizations. The field did not normally focus on the relationship of disparate employment practices on overall organizational performance or on the systematic relationships among such practices. The field also lacked a unifying paradigm.

HRM developed in response to the substantial increase in competitive pressures in business organizations began experiencing by the late 1970s as a result of such factors as globalization, deregulation, and rapid technological change. These pressures gave rise to an enhanced concern on the part of firms to engage in strategic planning - a process of anticipating future changes in the environment conditions (the nature as well as level of the market) and aligning the various components of the organization in such a way as to promote organizational effectiveness.

Taslim Ahammad, Assistant Professor/Proctor, Bangabandhu Sheikh Mujibur Rahman Science \& Technology University (BSMRSTU). Email: taslim.ahammad@gmail.com. 
An organization's HRM function focuses on the people side of management. It consists of practices that help the organization to deal effectively with its people during the various phases of the employment cycle, including pre-hire, staffing, and post-hire. The pre-hire phase involves planning practices. The organization must decide what types of job openings will exist in the upcoming period and determine the necessary qualifications for performing these jobs. During the hire phase, the organization selects its employees. Selection practices include recruiting applicants, assessing their qualifications, and ultimately selecting those who are deemed to be the most qualified (Whatishumanresource.com, 2017).

\section{Historical Background of Personnel and HRM}

HRM has changed in name various times throughout history. The name change was mainly due to the change in social and economic activities throughout the history.

Industrial welfare: Industrial welfare was the first form of HRM. In 1833, the Factories Act stated that there should be male factory inspectors. In 1878, legislation was passed to regulate the hours of work for children and women by having a 60 -hour week. During this time, trade unions started to be formed. In 1868 , the 1st Trade Union Conference was held. This was the start of collective bargaining. In 1913, the number of industrial welfare workers had grown so a conference organized by Seebohm Rowntree was held. The Welfare Workers Association was formed later changed to Chartered Institute of Personnel and Development.

It is believed that the first personnel management department began at the National Cash Register Co. in the early 1900s, according to an HR Magazine article. After several strikes and employee lockouts, NCR leader John H. Patterson organized a personnel department to handle grievances, discharges, and safety, as well as training for supervisors on new laws and practices (whatishumanresource.com, 2017).

The history of personnel management begins around the end of the 19th century, when welfare officers (sometimes called "welfare secretaries") came into being. They were women and concerned only with the protection of women and girls. Their creation was a reaction to the harshness of industrial conditions, coupled with pressures arising from the extension of the franchise, the influence of trade unions and the labour movement, and the campaigning of enlightened employers, often Quakers, for what was called "industrial betterment". As the role grew, there was some tension between the aim of moral protection of women and children and the needs for higher output (CIPD, 2014).

The First World War speeded up change in the development of personnel management, with women being recruited in large numbers to fill the gaps left by men going to fight, which in turn meant reaching agreement with trade unions (often after bitter disputes) about "dilution" - accepting untrained women into craftsmen's jobs and changing manning levels.

During the 1920s, jobs with the titles of "labour manager" or "employment manager" came into being in the manufacturing industry and other industries where there were large factories, to handle absence, recruitment, dismissal and queries over bonuses and so on. Employers' federations, particularly in engineering and shipbuilding, negotiated national pay rates with the unions, but there were local and district differences and there was plenty of scope for disputes.

During the 1930s, with the economy starting to pick up, big corporations in these newer sectors saw value in improving employee benefits as a way of recruiting, retaining, and motivating workers. Nonetheless, older industries such as textiles, mining and shipbuilding which were hit by the worldwide recession did not adopt new techniques, seeing no need to do so because they had no difficulty in recruiting labour. 
The Second World War brought about welfare and personnel work on a full-time basis at all establishments creating war materials because an expanded Ministry of Labour and National Service insisted on it, just as the Government had insisted on welfare workers in munitions factories in the foregoing conflict. The Government saw specialist personnel management as part of the drive for greater efficiency and the number of people in the personnel function grew substantially; there were around 5,300 in 1943.

Around 1945, employment management and welfare work had become combined under the broad term "personnel management". Experience of the war had shown that output and efficiency could be influenced by employment policies. The role of the personnel function in wartime had been largely that of implementing the rules demanded by large-scale, state-governed production, and thus the image of an emerging profession was very much a bureaucratic one.

Following the growth of poor industrial relations during the 1960s, a Royal Commission under Lord Donovan was set up. Reporting in 1968, it was critical of both companies and unions; personnel managers were criticised for lacking negotiation skills and failing to plan industrial relations strategies. At least in part, Donovan suggested, these deficiencies were a concern of management's failure to give personnel management sufficiently high priority.

In the 1960s and 1970s, employment started to develop considerably. At the same time, personnel techniques developed using theories from the social sciences about motivation and organisational behaviour; selection testing became more widely used, and management training expanded. During the 1970s, specialism started to improve, with reward and resourcing, for example, being addressed as separate issues.

By the mid-1980s, the term "human resource management" arrived from the USA. The term "human resources (HR)" is a fascinating one: it seemed to suggest that employees were an asset or resource-like machines, but at the same time, HR also appeared to emphasise employee commitment and motivation.

Today's HR profession encompasses a number of specialist disciplines, including diversity, reward (including compensation, benefits, pensions), resourcing, employee relations, organisation development and design, and learning and development (the history of which is covered in detail in the next section of this factsheet). Most recently, in developing the Profession Map, the CIPD has defined 10 "professional areas" covered by the HR profession (CIPD, 2014).

\section{Discussion}

\section{Personnel Management}

Personnel management is an administrative function of a business that exists to provide the personnel needed for organizational activities and to manage the general employee-employer relationship. Personnel management can be defined as obtaining, using, and maintaining satisfied employees. It is an important part of management concerned with employees at work and with their relationship within the organization.

Personnel management is thus essentially an administrative record-keeping function, at the operational level. Personnel management makes efforts to maintain fair terms and conditions of employment, while at the same time, efficiently managing personnel activities for individual departments. It is expected that the outcomes from providing justice and achieving efficiency in the management of personnel activities will result eventually in achieving organizational success. 
Personnel management refers to the functions that many employers now refer to as Human Resources. These are the functions that Human Resources perform relative to the organization's employees and include recruiting, hiring, compensation and benefits, new employee orientation, training, and performance appraisal systems.

Personnel management also comprises developing and implementing policies and processes to create an orderly, employee-supportive work place. It is an older term that is falling into disuse in modern business organizations.

Personnel management is a term that is still used in various government agencies, and primarily in the non-profit sector, to describe the function that deals with the employment of people within the business organization. When thinking of it, though, most tend to think of the more transactional and administrative aspects of the HR management functions, however, others still use the term to refer to the whole range of HR responsibilities and services.

Moreover, the term, personnel management, brings forth images of employee unions, strict job classification systems, and established pay grades that leave line management with few management options.

The main problem with the personnel management view is that it leaves out the strategic components of the possible HRM role. It must include responsibility for training and organization development. On the other hand, these are not included in personnel management. Nor is the performance management system approach to developing employees and their careers.

\section{HRM}

In practice, the HR function within business organisations in the UK (and elsewhere) is infinitely flexible, organisationally contingent over time and driven principally by the external contexts of the age; and these often change within short periods of time. Undeniably, the history of HR in the UK and elsewhere shows that it has had to change its priorities and focus its actions by re-inventing itself continuously. It has been largely in response to external socio-economic factors beyond the immediate control of HR practitioners or senior managers. Because of these reasons, a variety of definitions, frameworks, and models can be found in any of the basic (or not so basic) texts and in the wide range of articles examining and exploring the functions, roles, and antecedents of contemporary HRM in organisations. Nevertheless, some understanding of the differing frameworks and intellectual underpinnings of HRM is necessary, if readers are to identify, recognize, and analyse the major external and internal contexts within which HR professionals operate nowadays.

One major text in the field, Marchington and Wilkinson (2008), defines HRM curtly as the management of employment. Another standard text provides no agreed definition of HRM but distinguishes between "soft" and "hard" versions of it. The soft HRM recognises employees as a resource worth investing in, and tends to focus on high commitment/high involvement human resource practices. Hard HRM "identifies employees as a cost to be minimised, and tends to focus on 'flexibility techniques' and limited investment in learning and development" (Beardwell \& Claydon, 2007). HRM in the English-speaking world is regarded as all those activities associated with the management of employment relationships in the firm (CIPD, 2014).

Hence, HRM is the process of recruitment, selection of employees, providing proper orientation and induction, providing proper training and the developing skills, assessment of employee (performance of appraisal), providing proper compensation and benefits, motivating, maintaining proper relations with labour and with trade unions, maintaining employees' safety, welfare and health by complying with labour laws of concern state or country. 
HRM is the function within an organization that focuses on recruitment of, management of, and providing direction for the people who work in the organization. HRM can also be performed by line managers.

HRM is the organizational function that deals with issues related to people such as compensation, hiring, performance management, organization development, safety, wellness, benefits, employee motivation, communication, administration, and training.

\section{HRM Functions}

HRM is all about balancing the organization's people and processes to best achieve the goals and the strategies of the organization, as well as the goals and the needs of workforces. The leading role an HR manager has to fulfil is to integrate business operations and strategies across a wide array of culture, products, and ideas, while effectively delegating work among HR specialists and line management.

Apart from being concerned with local issues of employees, HRM must deliberate below functions and effects of workforce diversity, legal restriction, performance management, training and professional development of the organization.

\section{Learning and Development (L\&D)}

L\&D strategy is an organisational strategy that articulates the workforce capabilities, skills, or competencies required to ensure a sustainable, successful organisation and that sets out the means of developing these capabilities to underpin organisational effectiveness (CIPD, 2014).

Organisational L\&D is of crucial and strategic importance. This is a matter not just of extensive training in task skills, but of completely new ways of thinking about work and of working and relating with one another. Individuals at all levels need to be able to think and work "outside the box". They need to be able to do so without prior experience, clear guidelines, or close supervision. Overall, this amounts to the need for using high levels of cognitive skills, including learning how to learn. It also amounts to the need for managers to train and develop their existing workforce, facilitate their learning within a learning culture, and with appropriate resources, and train and develop new employees. And beyond the organisation, it amounts to the need to develop a learning society.

Learning is a process within the organism which results in the capacity for changed performance which can be related to experience rather than maturation (Ribeaux \& Poppleton, 1978). It is now widely recognised that intelligence is not just a cognitive capacity - note the theory of multiple intelligences (Gardner, 1985), and the recent interest in emotional intelligence (Pickard, 1999). Hence, learning is not just a cognitive process that involves the assimilation of information in symbolic form (as in book learning), but is also an affective and physical process (Binsted, 1980). Our emotions, nerves, and muscles are involved in the process, too. Learning leads to change, whether positive or negative for the learner. It is an experience after which an individual "qualitatively changed the way he or she conceived something" (Burgoyne \& Hodgson, 1983, p. 393) or experienced "personal transformation" (Mezirow, 1977). Learning can be more or less effectively undertaken, and it can be more effective when it is paid conscious attention. Development, however, is the process of becoming increasingly complex, more elaborate and differentiated, by virtue of learning and maturation. ${ }^{1}$ In an organism, greater complexity, differentiation among the parts, leads to changes in the structure of the whole and to the way in which the whole functions (Reese \& Overton, 1970). In the individual, this greater complexity

\footnotetext{
${ }^{1}$ As will be noted later, it is sometimes assumed that development connotes progression and advancement.
} 
opens up the potential for new ways of acting and responding to the environment. This leads to the opportunity for even further learning, and so on. Learning therefore contributes to development. It is not synonymous with it, but development cannot take place without learning of some kind (Collin, 2001).

Training and development. The HRM department is responsible for providing on-the-job as well as refresher training for all employees who were newly hired and for the existing. This one of the most important function and lack of training opportunities only increases frustration levels among employees. Thus, training systems must be streamlined across all locations in order to make communication and sharing of resources a convenient task. Measurement and monitoring is another vital aspect of training in order to foster adoption of employees' new skills.

Training and development is a function of HRM concerned with organizational activity aimed at bettering the performance of individuals and groups in organizational settings. This has been known by several names, including "human resource development (HR development)" and "L\&D".

\section{Recruitment and Selection}

Recruitment is the process of having the right person, in the right place, at the right time. It is crucial to organisational performance. Recruitment is a critical activity, not just for the HR team but also for line managers who are increasingly involved in the selection process. All those involved in recruitment activities should be equipped with the appropriate knowledge and skills (CIPD, 2014).

The great deal of consideration and resources is required to attract, hire, and retain an experienced, committed, and well-motivated workforce. This is perhaps one of the most basic HR functions. There are several essentials to this task, such as developing a job description, advertising the job postings, screening applicants, conducting interviews, making offers, and negotiating salaries and benefits. Corporations that value their people put a serious amount of investment in recruiting and staffing services. As the right set of talented employees can not only raise the companies profile but also help it achieve profitability and keep it running effectively and productively.

\section{Professional Development}

Operational HR departments allow and encourage the workforces with opportunities for growth, leadership training and education, which in turn contribute to the success of the company. Sponsoring for career advancement seminars, training, corporate social responsibilities and trade shows will make employees feel important and cared for by the team and business.

\section{Performance Appraisal}

Performance appraisal (or performance review) is a process for individual employees and those concerned with their performance, typically line managers, to engage in a dialogue about their performance and development and the support they need in their role. It is used to both assess recent performance and focus on future objectives, opportunities, and resources needed (CIPD, 2014).

The performance appraisal is a review and discussion of an employee's performance of assigned duties and responsibilities. The appraisal is based on results obtained by the employee in his/her job, not on the employee's personality characteristics.

This process also referred to as a performance review, performance evaluation, (career) development discussion, or employee appraisal is a method by which the job performance of an employee is documented and evaluated. 


\section{Benefits and Compensation}

The corporation is more likely to be successful, if it adapts new ways of providing benefits to workforces. More or less, non-traditional benefits that can attract and retain new skilled workers are:

(1) Flexible working hours or workdays;

(2) Extended vacation time;

(3) Paternity leave or childcare;

(4) Medical/dental insurance;

(5) Corporate gym membership discounts;

(6) Continuing education/skills development;

(7) Award \& recognition programs;

(8) Health care insurance;

(9) Life insurance;

(10) Disability insurance;

(11) Retirement;

(12) Voluntary accidental death and dismemberment insurance;

(13) Leave transfer program;

(14) Tuition assistance plan;

(15) Training opportunities.

\section{Ensuring Legal Compliance}

HRM keeps the compliance with labour, tax, and employment laws, which is a vital part of safeguarding the organization's continued existence. HR has to be aware of all the mandate laws and policies regarding employment practices, working conditions, tax allowances, required working hours, overtime, break times, minimum wage, and discrimination policies as noncompliance can affect productivity and ultimately, profitability of the company.

\section{Equality and Diversity}

Equality. Equality is ensuring individuals or groups of individuals are treated fairly and equally and no less favourably, specific to their needs, including areas of race, gender, disability, religion or belief, sexual orientation and age. Promoting equality should remove discrimination in all of the aforementioned areas. Bullying, harassment, and victimization are also considered as equality and diversity issues.

Diversity. Diversity aims to recognise, respect, and value people's differences to contribute and realise their full potential by promoting an inclusive culture for all staff and students.

Promote equality and diversity. The best possible ways to promote equality and diversity are as follows:

(1) Treating all staffs fairly;

(2) Creating an inclusive culture for all employees;

(3) Ensuring equal access to opportunities to enable employees to fully participate in the learning process;

(4) Enabling all staff to develop their full potential;

(5) Equipping staff with the skills to challenge inequality and discrimination in their work/study environment;

(6) Making certain that any learning materials do not discriminate against any individuals or groups;

(7) Ensuring that policies, procedures, and processes do not discriminate any one. 


\section{HR Strategy}

Strategic HR is the strategic management of human resources aligned with the organisation's intended future direction. It is concerned with longer-term people issues and macro-concerns about structure, quality, culture, values, commitment and matching resources to future need. You will find here information on HR strategy, HR capability, alignment of the HR function with business strategy, and the contribution of HR to business performance (CIPD, 2014).

The globalization of individual businesses and capital markets over the past two decades has changed the business scenery. The maximum of companies have expanded operations overseas, and even strictly domestic businesses are facing competition from overseas.

HR strategy needs to be affiliated with the organization's vision, mission, and goals. Within developing an HR strategy, the company must analyse the characteristics of its industry, determine its competitive advantage, and identify key processes and main individuals. Generating different strategies for all groups of people in the organization may be necessary, depending on their skills, knowledge, and accountabilities.

\section{Conclusion}

This research is based on a comprehensive review of related literature and thorough examination of the HRM studies. It introduced careful thought, analysis, and research in a conscientious effort to explore HRM. The author hope this study will open new dimensions for other researchers to carry more research in the field to crystallise other related issues, which can contribute to the knowledge and enhancement of HRM practices within the world.

In the context of HRM, organizations are increasingly encouraged to implement a range of practices which, as is argued, will improve their competitiveness in the global market area. Therefore, change initiatives within organisations follow one after the other. Thus far, although there is apparent acceptance among practitioners and academics that evaluation is a crucial step in any process of continual improvement, the reality is often that little has been done to assess the impact and degree of success of each initiative before organisations progress to the future.

HRM now anticipated adding value to the strategic application of employees and that employee programs impact the business in measurable ways. Hence, the new role of HRM involves various functions, strategic direction and measurements to determine worth.

\section{References}

Beardwell, J., \& Claydon, T. (2007). Human resource management: A contemporary approach (5th ed.). Harlow: FT/Prentice Hall.

Binsted, D. S. (1980). Design for learning in management training and development: A view. Journal of European Industrial Training, 4(8), 2-32.

Burgoyne, J. G., \& Hodgson, V. E. (1983). Natural learning and managerial action: A phenomenological study in the field setting. Journal of Management Studies, 20(3), 387-399.

CIPD. (2014). Retrieved from http://www.cipd.co.uk/hr-resources/factsheets/history-hr-cipd.aspx

CIPD. (2014). Retrieved from http://www.cipd.co.uk/hr-resources/factsheets/recruitment-overview.aspx

CIPD. (2014). Retrieved from http://www.cipd.co.uk/hr-topics/strategic-hr.aspx

Collin, A. (2001). Chapter 7: Learning and development. In I. Beardwell, \& L. Holden (Eds.), Human resource management: A contemporary approach (pp. 272-323). Harlow: Pearson Education Limited.

Gardner, H. (1985). Fames of mind: The theory of multiple intelligences. London: Paladin. 
Marchington, M., \& Wilkinson, A. (2008). Human resource management at work: People management and development (4th ed.). London: CIPD.

Mezirow, J. (1977). Personal transformation. Studies in Adult Education (Leicester: National Institute of Adult Education), 9(2), 153-164.

Pickard, J. (1999). Emote possibilities: Sense and sensitivity. People Management, 5(21), 48-56.

Reese, H. W., \& Overton, W. F. (1970). Models of development and theories of development. In L. R. Goulet, \& P. B. Baltes (Eds.), Life-span developmental psychology: Theory and research (pp. 115-145). New York, NY: Academic Press.

Ribeaux, P., \& Poppleton, S. E. (1978). Psychology and work: An introduction. London: Macmillan.

Whatishumanresource.com. (2017). The historical background of human resource management. Retrieved from http://www.whatishumanresource.com/the-historical-background-of-human-resource-management 